\title{
Saprophytic growth of the alder rust fungus Melampsoridium hiratsukanum on artificial media
}

\author{
Salvatore MORICCA*, Beatrice GINETTI \\ DISPAA, Dipartimento di Scienze delle Produzioni Agroalimentari e dell'Ambiente, Università di Firenze, \\ Piazzale delle Cascine 28, I 50144 Firenze, Italy
}

\section{A R T I C L E I N F O}

\section{Article history:}

Received 7 August 2014

Received in revised form

12 February 2015

Accepted 3 March 2015

Available online 14 March 2015

Corresponding Editor:

Paul Birch

\section{Keywords:}

Exotic rust

Invasive species

In vitro growth

Sporulation

Urediniospores

\begin{abstract}
A B S T R A C T
The first axenic culture of a free living saprophytic stage of the exotic rust fungus Melampsoridium hiratsukanum is reported. Colonies were obtained from one-celled, dikaryotic urediniospores on eight nutrient media out of twelve. Modified Harvey and Grasham (HG) and Schenk and Hildebrandt (HS) media HG1 and SH1 and their bovine serum albumin (BSA)enriched derivatives gave abundant mycelial growth, but modified Murashige and Skoog (MS) QMS media and their BSA-enriched modifications performed poorly, colony growth being low on QMS-1 and QMS1+BSA, and nil on QMS-5 and QMS-6, with or without BSA. Colonies initially grew poorly when subcultured for one month in purity, but much better after re-transfer to fresh media later: presumably because only the most exploitative genotypes survived, best able to cope with an uncongenial medium. Stabilised cultures survived, and remained vegetative, but only few reproductive colonies produced spore-like bodies. Though the agarised medium remains an inhospitable environment for this biotrophic parasite, it is shown that non-living media can nevertheless sustain the growth and sporulation of this fungus outside its natural hosts and habitat. Axenic culture promises important advances in basic and applied research on this rust, leading to a better understanding of its nutrition, metabolism, diversity and pathogenicity.
\end{abstract}

( 2015 The British Mycological Society. Published by Elsevier Ltd. All rights reserved.

\section{Introduction}

A number of microbes that cannot be cultured in vitro cause diseases to plants in both natural and agricultural settings. Among these, prominent are the rust fungi (Basidiomycota, Uredinales), which cause serious diseases like coffee rust (Hemileia vastatrix Berk. \& Broome), cereal rusts (Puccinia spp.), pine blister rusts (Cronartium spp.) and poplar rusts (Melampsora spp.). The importance of finding ways to grow these biotrophic microbes axenically was already stressed in a 1951 editorial in Nature (Anonymous 1951). Despite numerous efforts made since then, however, most attempts to culture these agents have proved unsuccessful (Williams 1984; Staples 2000), and so far only very few of the 7000 or so recognised species in the Urediniomycetes (mostly members of the Cronartiaceae and Pucciniaceae) have been cultured in vitro. The rust fungus Melampsoridium hiratsukanum S. Ito ex Hirats. (Pucciniastraceae) poses a serious menace to natural stands and plantations of alder in several countries of central and eastern Europe. A native of eastern Asia (Hiratsuka 1927), this invasive parasite was first reported in the Baltics in the mid-1990s, where it arrived presumably through the trade in nursery plants (Põldmaa 1997; Hantula \& Scholler 2006; Hantula et al. 2009). In the last twenty years it has spread

\footnotetext{
* Corresponding author. Piazzale delle Cascine 28, I 50144 Firenze, Italy. Tel.: +39055 2755864.

E-mail address: salvatore.moricca@unifi.it (S. Moricca).

http://dx.doi.org/10.1016/j.funbio.2015.03.002

1878-6146/@ 2015 The British Mycological Society. Published by Elsevier Ltd. All rights reserved.
} 
epidemically across a number of countries along a north-south axis roughly running from latitude $60^{\circ} \mathrm{N}$ (Finland) to latitude $38^{\circ} \mathrm{N}$ (Turkey), parasitising a number of the alder species (Alnus incana Moench., Alnus cordata Loisel, Alnus glutinosa Gaertn., Alnus orientalis Decne., and Alnus viridis D.C.) it encountered in its fairly rapid descent southwards (Kreisel \& Scholler 1994; Piątek et al. 2001; Szabo 2002; Rigler-Hager et al. 2003; Sert \& Sümbul 2005). The fungus has also recently been reported on grey alder (A. incana) in the eastern sector of the Italian Alps (Lagorai mountain range, Trentino AltoAdige region) (Moricca \& Maresi 2010). Subsequent surveys have revealed that the rust agent is spreading pervasively in several Alpine valleys, hundreds of kilometres from where it was first reported in Italy.

Melampsoridium hiratsukanum is a heteroecious rust fungus which develops its sexual (aecial) stage on larch (Larix sp.) and its asexual (uredinial) stage on alder (Alnus sp.) (Fig 1A-D) (Wilson \& Henderson 1966). The host-alternating rust fungus spreads from larch (Fig 1A) in spring, when the newlydeveloped aeciospores are windborne to alder. On alder the fungus differentiates its uredinia (Fig 1B). The uredinial pustules produce urediniospores, a repeating (clonal) stage by means of which the fungus intensifies its infection of the leaves of the same or adjacent alder trees, causing the defoliation of these trees in early summer. The fungus overwinters on the alder leaves with its telial stage, and the following spring re-infects larch through its basidiospores (Fig 1C). A couple of months later, it then spreads back to alder by means of its aecial stage, starting the whole cycle anew. The seasonal and diurnal release of urediniospores causes repeated waves of infection that may be lethal to alder if it is severe for two consecutive years (Fig 1D). Host-alternation does not however seem obligatory in the life-cycle of $M$. hiratsukanum, for it has been hypothesised that it also has a shortened life-cycle, in which it survives as mycelium on the buds of infected alders, or as urediniospores, perpetuating the rust infection on alder from year to year without requiring larch as an intermediate host (Rigler-Hager et al. 2003; Hantula \& Scholler 2006). Such a shortened life-cycle would be consistent with the high infection levels that are typical of rusts repeatedly infecting the same host.

Melampsoridium hiratsukanum drastically reduces alder fitness, causing heavy defoliation, stunted growth, decreased reproduction and host death. By its strong parasitic action, the fungus is currently endangering alder species and riparian ecosystems in some Alpine valleys, thus compromising important ecosystem services provided by alder, such as the watershed protection offered by riparian alder formations (G. Maresi, pers comm.).

Besides M. hiratsukanum, three other species of Melampsoridium, Melampsoridium alni (Thüm.) Dietel, Melampsoridium betulinum (Pers.) Kleb., and Melampsoridium carpini (Nees) Dietel also occur on representatives of the family Betulaceae (members of the genera Alnus, Betula, Carpinus, Corylus, and Ostrya) in the northern hemisphere (Wilson \& Henderson 1966). Likewise M. hiratsukanum, M. alni, and M. betulinum also infect the genus Alnus (Gäumann 1959; Roll-Hansen \& Roll-Hansen 1981; Hantula et al. 2009) and these fungi have long been recorded in the Italian Peninsula (Trotter 1914; Saccardo 1988, 1905).

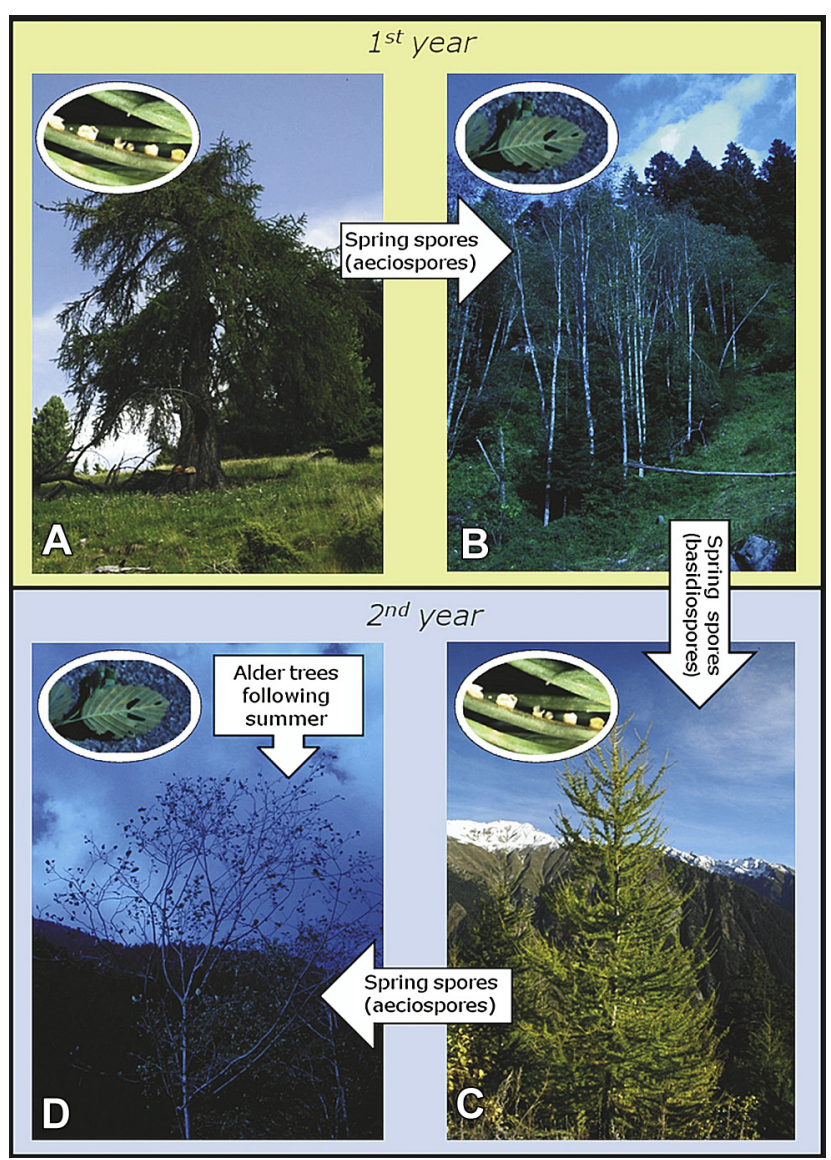

Fig 1 - The life cycle of Melampsoridium hiratsukanum on its aecial host (Larix sp.) and its telial host (Alnus sp.). (A) In May and June - depending on environment and altitude orange-yellow blisters break through the epidermis of infected larch needles; the blisters contain M. hiratsukanum aeciospores that at maturity are windborne to the alternate host (alder). (B) After 2-3 weeks, minute orange-yellow pustules (uredinia) develop on the underside of alder leaves. Urediniospores are repeatedly produced during summer, and when conditions are favourable, alders may be completely defoliated as early as the beginning of July. From midsummer to the end of the growing season the telial stage occurs syntopically with the uredinial stage on the alder leaves. The telia cause differentiation of the teliospores, thick-walled, overwintering spores that germinate the following spring to produce the basidia. Each basidium generates four haploid basidiospores, which re-infect larch (C). On larch the fungus first develops its spermogonial stage, producing spermatia, and then its aecial stage, forming aeciospores, so that (D) the infection cycle can start all over again. (For interpretation of the references to colour in this figure legend, the reader is referred to the web version of this article.)

The near resemblance of M. alni, M. betulinum, and M. hiratsukanum to each other makes it often difficult to identify them to species level, and the reliability of many older records is therefore doubtful. However, a close study of some micromorphological characteristics and molecular examination has 
enabled these Melampsoridium species to be distinguished (Kurkela et al. 1999; Moricca \& Maresi 2010).

Obtaining a culture of a plant pathogen in the laboratory is always a fundamental first step in the investigation of any host-parasite system. As with other rust fungi, research on M. hiratsukanum has been much hampered by the lack of pure living mycelium as starting material to study the disease. If a way could be found to grow this biotrophic plant parasite (which by its very nature is unfit for a saprophytic existence) axenically, it would allow unprecedented investigations to be undertaken on fundamental aspects of its biology, and would facilitate studies on its nutrition, sexuality, lifehistory strategy and pathotypic variation. The aim of this study was to find a way to grow M. hiratsukanum axenically on a range of artificial media.

\section{Materials and methods}

\section{Inoculum source}

The original inoculum came from about 500 grey alder leaves collected from naturally infected alder trees in the Val Campelle, a narrow Alpine valley close to the wider Valsugana valley, in Trentino Alto-Adige (northern Italy), latitude $46^{\circ} 07^{\prime} 30^{\prime \prime}$ $\mathrm{N}$; longitude $11^{\circ} 29^{\prime} 47^{\prime \prime} \mathrm{E}$; altitude $900-1000 \mathrm{~m}$ a.s.l. Leaves were collected at the end of July 2012, when the rust infection was at the mature uredinial stage, with the lower surface of infected leaves densely covered by yellow-orange urediniospores, discharged through uredinial pustules (urediniosori).

\section{Inoculum storage}

Leaves infected with Melampsoridium hiratsukanum were placed in wet polyethylene bags to maintain a high relative humidity, and stored at $4{ }^{\circ} \mathrm{C}$ for a few hours until use. The remaining infected host material was stored in sterile filter paper bags to achieve rapid dehydration of the leaf tissues and prevent contamination with other common phylloplane saprophytic fungi. These dried voucher specimens were stored in the herbarium of the Department Agri-food Production and Environmental Sciences, Plant Pathology and Entomology Division, in Florence.

\section{Conventional identification of environmental samples}

Light-microscopic and ultrastructural inspection were carried out to ensure that the rust fungus infecting the alder leaves was effectively Melampsoridium hiratsukanum. A great number of spores was gathered from the freshly collected alder leaves, mounted on glass slides in lactophenol-cotton blue and examined under a Carl Zeiss Axiophot ${ }^{\odot}$ dissecting microscope at $\times 40$ and $\times 63$ magnification. The following micromorphological characters were used to distinguish $M$. hiratsukanum from the related Melampsoridium alni and Melampsoridium betulinum: the shorter and wider urediniospores of $M$. hiratsukanum (21-34 $\times 10-15 \mu \mathrm{m})$; the lack of or a less marked smooth area at the cell apex of this fungus; and the much longer ostiolar cells of its peridia in the urediniosori (Wilson \& Henderson 1966).
Leaf fragments (approximately $1 \mathrm{~cm}^{2}$ square) were also cut from 15 randomly chosen infected leaves to inspect the rust sori and propagules in the scanning electron microscope (SEM). The leaf fragments were dried in a Bal-Tec 030 critical-point drier using liquid $\mathrm{CO}_{2}$. The dried leaf samples were then cut into 40 - $\mu \mathrm{m}$-thick slices using a microtome cryostat (Cryo-Cut Microtome, American Optical Corp., Scientific Instrument Div., Buffalo, NY, USA) for a detailed examination of the rust spores, and the fruiting bodies were inspected in cross-section. Samples were sputtered with gold palladium film using an S105A Edward sputter coater and examined with a Philips 505 SEM at $20 \mathrm{kV}$.

\section{Culture media}

Twelve nutrient media, including six basic media, and these same six media enriched with $10 \mathrm{~g} \mathrm{l}^{-1}$ filter-sterilised BSA, were tested for their capacity to support the growth of Melampsoridium hiratsukanum. Six of these media (three basic media plus their BSA-enriched counterparts) were designated by sigla beginning with the prefixes HG and SH since they were modifications of media originally devised by Schenk \& Hildebrandt (1972) and Harvey \& Grasham (1974). The composition of these media for this study was as described in Moricca \& Ragazzi (2001). These six media had already been found to support the growth of the two-needle pine rust Cronartium flaccidum from aeciospores (Moricca \& Ragazzi 1994 1996), of the poplar rust Melampsora larici-tremulae, also from aeciospores (Moricca et al. 2000), and of C. flaccidum from basidiospores (Moricca \& Ragazzi 2001), but they had never been tested for their capacity to support the axenic growth of any rust fungus from urediniospores.

The remaining six media tested were the three basic media QMS-1, QMS-5 and QMS-6, all of which had produced good axenic growth of Melampsoridium betulinum (a close relative of M. hiratsukanum) from its urediniospores (Yamaoka \& Katsuya 1984), plus these same media amended with BSA as above: QMS-1+BSA, QMS-5+BSA, and QMS-6+BSA. Care was taken to add the BSA to the flasks, and mix it uniformly, only when the media had been cooled to a temperature near the solidifying point, just before they were poured into the Petri dishes. All the media were gelified by adding $5 \mathrm{~g} \mathrm{l}^{-1}$ of Difco Bacto Agar (DBA) (Difco Laboratories Inc., Detroit, MI, USA). The pH was adjusted to 5.7-5.8 with $1 \mathrm{~N} \mathrm{HCl}$ and $1 \mathrm{~N}$ $\mathrm{NaOH}$ before autoclaving at $120{ }^{\circ} \mathrm{C}$ for $25 \mathrm{~min}$. Each Petri dish $(6 \mathrm{~cm}$ diam) contained $7 \mathrm{ml}$ of nutrient medium.

\section{Culturing experiments}

\section{Inoculation of media}

Three hundred 6-cm-diameter Petri dishes (25 dishes per medium) were utilised for the experiment. Leaf discs with a diameter of $5-5.5 \mathrm{~cm}$ were cut from infected alder leaves using a scalpel under a laminar flow cabinet, and including as much as possible of those areas that were most heavily infected. One or two 4-5-cm-long strips of double-sided adhesive tape were pressed to the inside of the lids of the Petri dishes, and the upper surface of the leaf discs was firmly attached to the tape, leaving the lower leaf surface exposed. 
The nutrient medium was then poured into the Petri dishes and the lids with the infected leaf discs adhering to them were placed back on the dishes so that the discs with the sporulating urediniosori exposed were suspended directly over the medium. The dishes were sealed with Parafilm $\mathrm{M}^{\mathrm{TM}}$ (American National Can, Menasha, WI, USA) and incubated at $20 \pm 2{ }^{\circ} \mathrm{C}$ in a growth chamber in darkness. After $72 \mathrm{~h}$, a length of time thought to be long enough to obtain a sufficient urediniospore cast, the lids with the leaf discs were removed and replaced with sterile lids without leaf discs. The Petri dishes were again sealed as above and incubated at $20 \pm 2{ }^{\circ} \mathrm{C}$ in the dark.

\section{Elimination of unwanted micro-organisms and colony subculturing}

Inoculated Petri dishes were inspected daily during the first week under the stereoscope and any contaminants were removed with a sterile scalpel upon their first appearance. This was a crucial step as contaminant micro-organisms, since they grow faster, tend to overgrow the slower-growing rust and this could have seriously compromised the culturing experiment. Urediniospore germination was determined after $48 \mathrm{~h}$ by inspecting 250 spores per medium (10 spores per dish) under the light microscope. Germ-tube elongation and hyphal branching were assessed using the growth scale of Kuhl et al. (1971). Mycelial initials of the rust were detected under the stereoscope after 3-4 d, and hyphal masses were clearly visible with the naked eye after one week. The mycelial primordia were individually subcultured under aseptic conditions in new Petri dishes containing the same contaminant-free media when the primordia reached a diameter of $2-3 \mathrm{~mm}$ (primary cultures). After one month, the primary cultures were subcultured again on newly prepared, fresh nutrient media (established cultures).

Primary and established cultures were transferred to new Petri dishes by gently lifting colonies from the agar surface with a sterile scalpel; this manipulation was facilitated by the fact that mycelium growth was only superficial; the hyphae did not penetrate into the medium.

Growth of primary and established colonies was measured at seven-day intervals during the first month, then once every month for the next eight months, by taking the orthogonal diameters of 25 randomly chosen replicates (each replicate consisting of one Petri dish) of each medium.

Molecular identification of saprophytic mycelium

Since colony shapes varied widely, to confirm that the colonies growing on the media were effectively Melampsoridium hiratsukanum, one colony of each shape found was identified to molecular level: one vegetative colony; one reproductive colony; one mucilaginous colony; one callus-like colony; and one 'variant' colony. Variant colonies did not differ from vegetative colonies except in growing more rapidly, but it was decided to identify a colony of this shape anyway to confirm that the faster-growing mycelium of these colonies was the same as that of the slower-growing mother colonies from which they originated, and was not a different, possibly contaminant mycelium. A total of five colony-types was therefore identified at DNA level.

A rapid DNA isolation protocol was followed to obtain amplifiable DNA from the scant mycelium provided by each colony. The mycelium was lifted from the agar surface with a sterile spatula, placed in $0.5-\mathrm{ml}$ microcentrifuge tubes with a $100-\mu \mathrm{m}$ TE buffer (10 mM Tris $\mathrm{HCl} \mathrm{pH} \mathrm{8.0,} 1 \mathrm{~mm}-$ EDTA). and heated to $95^{\circ} \mathrm{C}$ for $5 \mathrm{~min}$. The tubes were then immediately cooled on ice and centrifuged for $5 \mathrm{~min}$ at $13000 \mathrm{rpm}$. Two- $\mu \mathrm{m}$ aliquots of the resulting supernatant were used directly in the amplification reactions. The ITS15.8S-ITS2 rDNA region was amplified in standard PCR reactions using the universal primers ITS1 and ITS4 (Gardes \& Bruns 1993). Amplification was done in $25-\mu$ l volumes each containing: $0.2 \mu \mathrm{M}$ of each primer; $2.5 \mu \mathrm{l}$ of $10 \times$ Taq DNA polymerase buffer (10 mM Tris $\mathrm{HCl} \mathrm{pH} \mathrm{8.3;} 1.5 \mathrm{~mm} \mathrm{MgCl}_{2} ; 50 \mathrm{~mm}$ $\mathrm{KCl}$; and $0.1 \mathrm{mg}$ gelatin); $200 \mu \mathrm{M}$ each of dATP, dCTP, dGTP, and dTTP; $2 \mu$ l of template DNA; and 0.5 unit of Taq DNA polymerase (Promega, Madison, WI, USA). Incubation was done in a GeneAmp PCR 9600 thermal cycler (Applied Biosystem Division, Foster City, CA, USA) using the following cycling programme: $60 \mathrm{~s}$ denaturation at $94{ }^{\circ} \mathrm{C}$; $60 \mathrm{~s}$ annealing at $50{ }^{\circ} \mathrm{C}$; and $120 \mathrm{~s}$ extension at $72{ }^{\circ} \mathrm{C}$. The total number of cycles was 37 , with an initial denaturation step of $2 \mathrm{~min}$ at $94^{\circ} \mathrm{C}$ and a final extension step of $8 \mathrm{~min}$ at $72{ }^{\circ} \mathrm{C}$. A negative control with all reagents except DNA was included in all reactions. PCR products were visualised on $1 \%$ agarose gel (Sigma-Aldrich) in $1 \times$ TAE (40 mM Tris-acetate, $1 \mathrm{mM}$ EDTA, pH 8.2) buffer. Both strands of purified amplicons were sequenced. Identification was by comparison with the sequences available in the GenBank database assuming sequences to be identical at the species level if their similarity was greater than $98 \%$ (Sánchez Márquez et al. 2008).

\section{Data analysis}

Urediniospore germination percentages (mean values) were separated after arcsine transformation with Fisher's Least Significant Difference (LSD) test using Statistica software (Statsoft, Tulsa, OK, USA). Significant differences (at $\mathrm{P}=0.05$ ) are shown in Table 1.

\section{Results}

\section{Identification of field-collected inoculum by light and electron microscopy}

Light and ultrastructural microscopy showed that the alder leaves were infected with Melampsoridium hiratsukanum and that no other species of Melampsoridium occurred on the leaf samples. Micromorphological features positively identifying the fungal structures as belonging to M. hiratsukanum were: a) the size, shape and ornamentation of the urediniospores, which were ovoid to ellipsoid and had a regular echinulation (spines finely distributed over the entire cell surface) (Fig 2A), all of which characterise M. hiratsukanum, whereas Melampsoridium betulinum and Melampsoridium alni produce narrower, more oblong spores with a smooth apex (no spines in the cell region); and b) the shape of the urediniosori, which were hypophyllous and subepidermal and had very long ostiolar cells (up to $40-50 \mu \mathrm{m}$ ) (Fig 2A and B); this shape characterises the urediniosori of $\mathrm{M}$. hiratsukanum, whereas the ostiolar 
Table 1 - Growth of Melampsoridium hiratsukanum colonies on twelve nutrient media, showing mean percentage of urediniospore germination, percentage of contamination, development of primary and established cultures, and number of sporulating colonies eight months after incubation.

\begin{tabular}{|c|c|c|c|c|c|c|}
\hline Medium & $\begin{array}{l}\text { Germina-tion } \\
(\%)^{\mathrm{a}}\end{array}$ & $\begin{array}{l}\text { Contamina-tion } \\
(\%)^{b}\end{array}$ & $\begin{array}{l}\text { No. of growing } \\
\text { colonies }\end{array}$ & $\begin{array}{c}\text { Growth of primary } \\
\text { cultures }{ }^{c}\end{array}$ & $\begin{array}{c}\text { Growth of established } \\
\text { cultures }^{\mathrm{d}}\end{array}$ & $\begin{array}{l}\text { No. of sporulating } \\
\text { colonies }^{e}\end{array}$ \\
\hline HG1 & $79 a$ & 56 & 87 & ++ & +++ & 5 \\
\hline HG1 + BSA & $77 a$ & 52 & 53 & ++ & +++ & 1 \\
\hline SH1 & $81 a$ & 48 & 47 & + & + & 4 \\
\hline $\mathrm{SH} 1+\mathrm{BSA}$ & $78 a$ & 44 & 65 & ++ & +++ & 6 \\
\hline HG1Y & $75 a$ & 64 & 79 & + & ++ & 2 \\
\hline $\mathrm{HG} 1 \mathrm{Y}+\mathrm{BSA}$ & $82 a$ & 52 & 74 & + & +++ & 3 \\
\hline QMS-1 & $84 a$ & 48 & 45 & + & + & 1 \\
\hline QMS-1 + BSA & $78 a$ & 56 & 68 & ++ & + & 2 \\
\hline QMS-5 & $53 b$ & 52 & 0 & - & - & - \\
\hline QMS-5 + BSA & $55 b$ & 44 & 0 & - & - & - \\
\hline QMS-6 & $48 b$ & 52 & 0 & - & - & - \\
\hline QMS-6 + BSA & $59 b$ & 48 & 0 & - & - & - \\
\hline \multicolumn{7}{|c|}{$\begin{array}{l}\text { a Values are the means of } 250 \text { spore counts per medium, made } 48 \mathrm{~h} \text { after inoculation. Percentage germination values followed by the same } \\
\text { letter do not differ significantly at } \mathrm{P}=0.05 \text {. } \\
\text { b Total assessment ( } 25 \text { Petri dishes per medium). } \\
\text { c Average assessment made } 1 \mathrm{~m} \text { after transfer to fresh medium: variations between cultures were sometimes considerable: } 0=\text { no growth; } \\
+=\text { trace growth (less than } 1 \mathrm{~mm} \text { per week); }++=\text { average growth }(1-2 \mathrm{~mm} \text { per week); }+++=\text { profuse growth (more than } 2 \mathrm{~mm} \text { per week). } \\
\text { d Average assessment made } 3 \mathrm{~m} \text { after transfer to fresh medium (same scale as in } \mathrm{fn} \text { ). } \\
\text { e Not determined in QMS5 and QMS6 with or without BSA as no colony growth was observed in these media. }\end{array}$} \\
\hline
\end{tabular}

cells of M. betulinum and M. alni are much shorter (Kurkela et al. 1999).

\section{Establishment of saprophytic mycelium}

Urediniospore germination (Table 1) did not differ significantly between any of our HG and SH media (HG1, SH1, HGY1) with or without BSA added. In these media it ranged from $75 \%$ to $82 \%$ (average $78,66 \%$ ). By contrast, urediniospore germination differed significantly between the modified Murashige \& Skoog (1962) (MS) QMS media: it was high on QMS-1 and QMS-1+BSA (84\% and $78 \%$ ), but significantly lower on QMS-5 and QMS-6, with or without BSA, where germination ranged from $48 \%$ to $59 \%$ (average $53,75 \%$ ), which was only about two thirds of the average germination percentage of all the media tested.

In all the media, sporeling growth, with germ-tube elongation and first hyphal branching, was clearly evident after about $48 \mathrm{~h}$. Germ tubes of sporelings varied greatly in length, with a number of long germ tubes (up to $400 \mu \mathrm{m}$ ) seen even before hyphal branching began (Fig 2C).

Saprotrophic mycelium (growth stage I on the scale of Khul et al. 1971) began to grow after two days; secondary and tertiary hyphal branching (growth stage II in that study) began after 48-72 h. The definitive transition from growth using only stored nutrients to growth wholly sustained by exogenous nutrients taken from the medium occurred in approximately the following $24 \mathrm{~h}$ (Khul et al. 1971). By that time hyphal branching became more intense and the hyphae initiated active growth, with the formation of dense, aerial hyphal aggregates (growth stage III). These aggregates developed into tight mats of mycelial primordia in the following week (growth stage IV) (Fig 2D).

Inoculum density appeared to be fundamental in inducing saprophytic growth in all the nutrient media. Urediniospores germinated most profusely where the agar medium had been most densely inoculated, with the sporelings appearing to stimulate one another's growth. Colonies also emerged more rapidly and were more numerous in areas where the inoculum cast had been greater.

\section{Removal of contaminant micro-organisms}

Despite repeated removal of microbial contaminants (of which the most numerous were Aureobasidium sp., Cladosporium sp. and Penicillium sp.), easily detectable by their faster growth, about $50 \%$ of inoculated dishes became irremediably contaminated and had to be discarded. This did not however compromise the experiment because of the high number of Petri dishes used as starting material. The number of Petri dishes that had to be discarded because they were too heavily contaminated (about 150) was amply compensated for by the many colonies that emerged from the successfully inoculated Petri dishes (Fig 2E), which produced more than 500 colonies (primary colonies), which could be individually subcultured in purity on fresh media after two weeks.

\section{Cultural features}

About $50 \%$ of hyphal aggregates failed to develop into individual colonies on some media. Of the aggregates that produced colonies, the time of colony emergence, the number of colonies obtained, and their subsequent growth varied depending on the medium (Table 1).

Primary colonies grew very slowly at the start of the culturing experiment (lag phase). After 2-3 weeks, colonies began to grow more profusely, especially on HG1, HG1+BSA, SH1+BSA, and QMS-1+BSA, whereas colony growth remained somewhat slower on SH1, HG1Y, HG1Y + BSA, and QMS-1. On QMS-5, QMS-5+BSA, QMS-6, and QMS-6+BSA no visible colonies formed even after four weeks, although some germlings had 

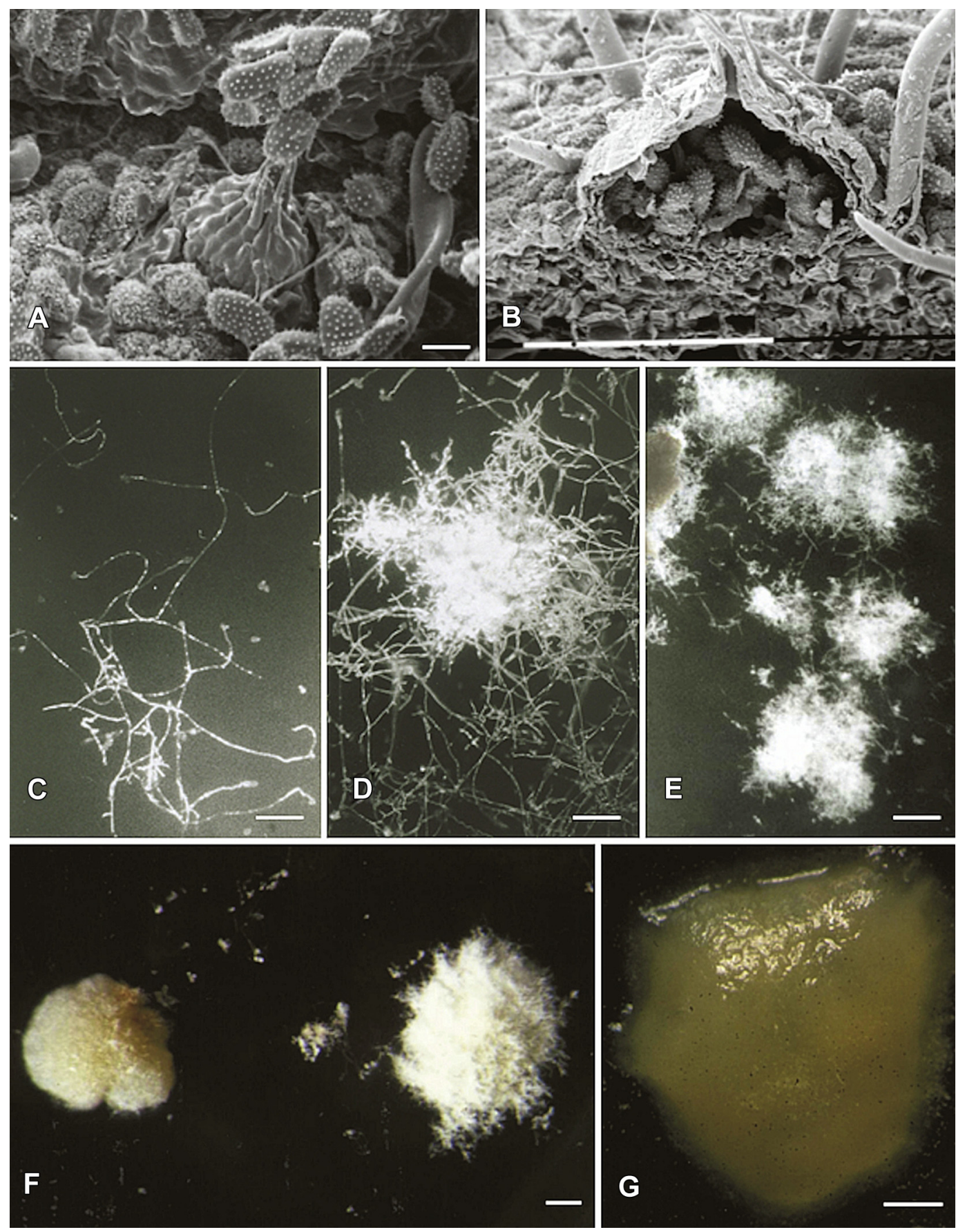

Fig 2 - Sori and urediniospores of Melampsoridium hiratsukanum in nature and growth of the fungus in axenic culture. (A-B) Scanning electron micrographs of portions of the lower surface of naturally-infected grey alder leaves; (A) a sub-epidermal, erumpent urediniosorus discharging urediniospores through its long ostiolar cells, which terminate in sharp spines. Note the typical ovoid to ellipsoid urediniospores with ornamentations spread all over the cell surface. Scale bar $=15 \mu \mathrm{m}$. (B) Cross-section of a leaf with a urediniosorus. The typical, elongated ostiolar cells, and the urediniospores produced within the receptacle can be seen. Scale bar $=100 \mu \mathrm{m}$. (C-G) The fungus at various stages of saprophytic development; (C) sporelings with elongating germ tubes, start of hyphal branching, and the first aggregations, $72 \mathrm{~h}$ after seeding on the agar medium. Scale bar $=100 \mu \mathrm{m}$. (D) A dense network of sporelings that have aggregated to produce the first mycelial primordium after 1 week. Scale bar $=0.5 \mathrm{~mm}$. (E) Mycelial initials differing in age, visible to the naked eye after $10 \mathrm{~d}$ of incubation. Scale bar = $1 \mathrm{~mm}$. (F) Two colonies growing side by side but varying in their shape and texture: the colony on the left is off-white to beige, with a compact texture, a dense cover of short hyphae, and a distinct margin; the colony on the right has a white, aerial mycelium, a fuzzy margin, and a looser texture. Scale bar $=1 \mathrm{~mm}$. (G) A pale yellow colony, with a mucilaginous, translucent surface, and a distinct margin. Scale bar $=1 \mathrm{~mm}$. (For interpretation of the references to colour in this figure legend, the reader is referred to the web version of this article.) 
grown and had produced scant saprophytic hyphae by that time. In all, eight of the twelve media tested supported saprophytic growth of Melampsoridium hiratsukanum (Table 1). HG1 had the best mycelial growth, producing the greatest number of growing colonies (87), all with luxuriant colony growth, as well as five sporulating colonies. HG1Y and HG1Y + BSA likewise gave rise to a good number of colonies, with respectively 79 and 74 colonies displaying fair or abundant growth. SH1+BSA produced somewhat fewer colonies (65) but all of these had abundant mycelium, which also yielded the greatest number of sporulating colonies (6). On QMS-1+BSA there was a good number of growing colonies (68), especially at the initial stages of the culturing experiment, but these colonies grew only poorly later, producing scant saprophytic hyphae (2).

On all media, primary colonies exhibited many variations in appearance, type of margin, mycelium texture, surface topography, and other macroscopic features. Some colonies were white and fluffy, with an indistinct margin, and they grew rapidly (Fig $2 \mathrm{~F}$, colony on the right). Other colonies were white tending to beige, and felty, with a more compact texture, a distinct margin and much poorer, almost negligible growth (Fig $2 \mathrm{~F}$, colony on the left). The mycelium of primary colonies consisted mainly of short, twisted, and highly branched hyphae whose growth was erratic. Many slow-growing colonies later turned brown to dark-brown, others assumed a leathery, callus-like, or 'cerebroid' appearance. A few colonies turned mucilaginous and translucent (Fig 2G) and their growth became stagnant or very slight. A considerable number of these anomalous stagnant colonies (about 40-50 \%) ceased growth altogether and had an atrophied appearance after a week. Such atrophied colonies were seen in all media, with no appreciable difference between them. Those colonies that showed stagnant growth but survived changed their appearance and texture, turning translucent and gradually becoming covered with short, thin, orange or, more rarely, whitish hyphae. Some leathery colonies later resumed growth and became overgrown with a dense aerial mycelium having a felty texture.

Colony growth changed drastically when colonies were transferred to fresh media after $1 \mathrm{~m}$. On these media cultural variations between media were much reduced, colonies became less fluctuating, grew faster and at a more constant rate (Table 1; Fig 3). Established cultures remained stable for the entire eight-month duration of the experiment, with the topography, texture, and compactness all remaining constant. These colonies now fell into two types: vegetative colonies and reproductive colonies. Vegetative colonies were white to cream-coloured with a dense aerial mycelium (Fig 4A), and grew at a constant rate (average $2 \mathrm{~mm}$ per month), but did not sporulate. Reproductive colonies on the other hand grew very slowly (0,5-1 mm per month), were covered with sparse, short hyphae, had brown to dark-brown stromatal areas on a rough, callus-like surface (Fig 4B), and produced spore-like bodies in culture.

Variant colonies also occasionally arose on a medium. These colonies were easily distinguishable from the wildtype mother colonies because they grew faster and had straight, generally unbranched hyphae that gave them a white colour and a looser texture.

Because of mass spore inoculation, some of the colonies as they grew became so inextricably intertwined with each other, as to appear a single colony, although in some cases individual colonies could still be distinguished by their distinctive colour, from creamy white to beige to dark-brown (Fig 4C).
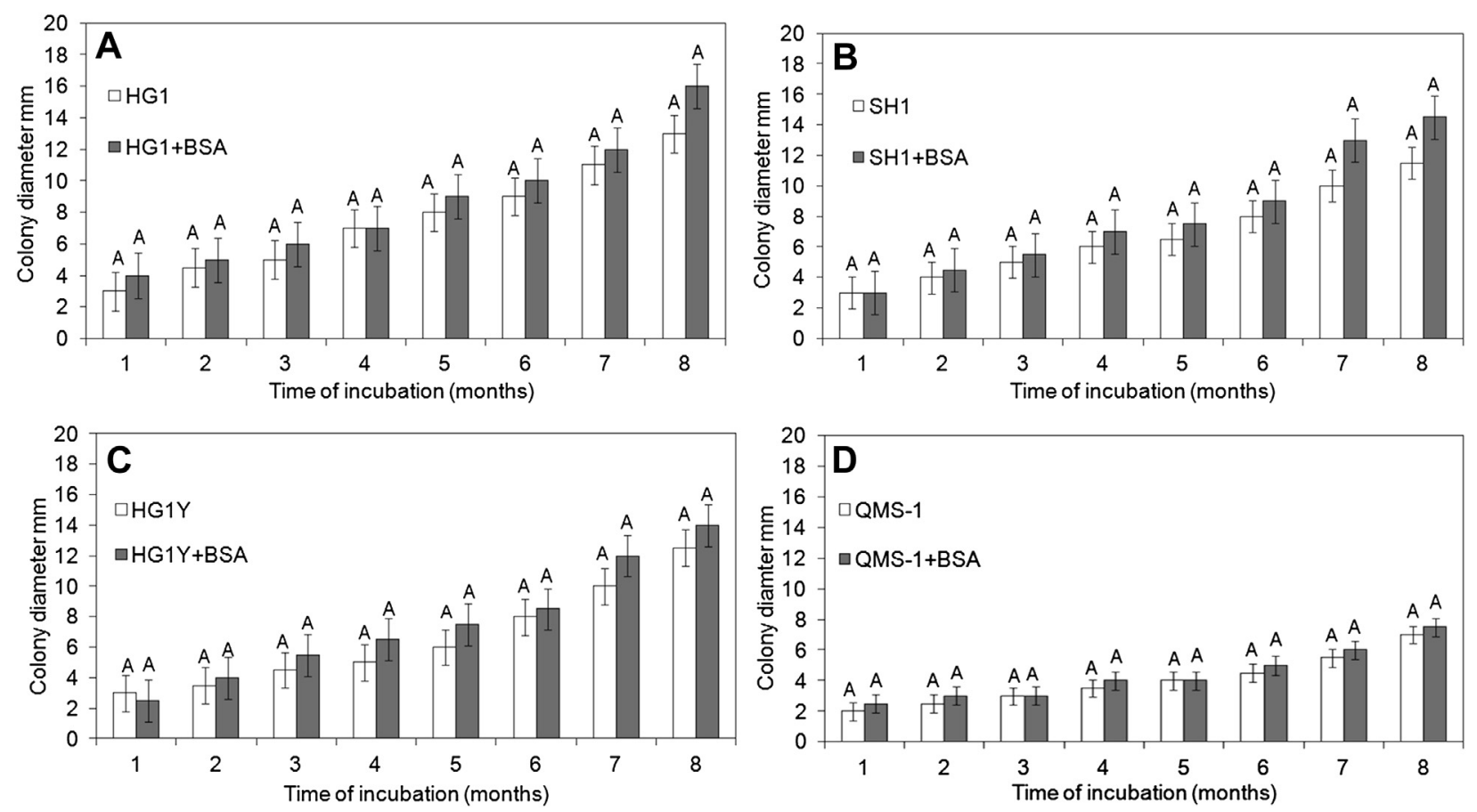

Fig 3 - Average monthly growth of colonies of Melampsoridium hiratsukanum for eight months. The fungus was incubated on four basal media: HG1 (A), SH1 (B), HG1Y (C), and QMS-1 (D), and on these same media with BSA added to them to promote fungal growth. Bars represent the standard error of the mean. Means with the same letter are not significantly different at $P=0.05$. 


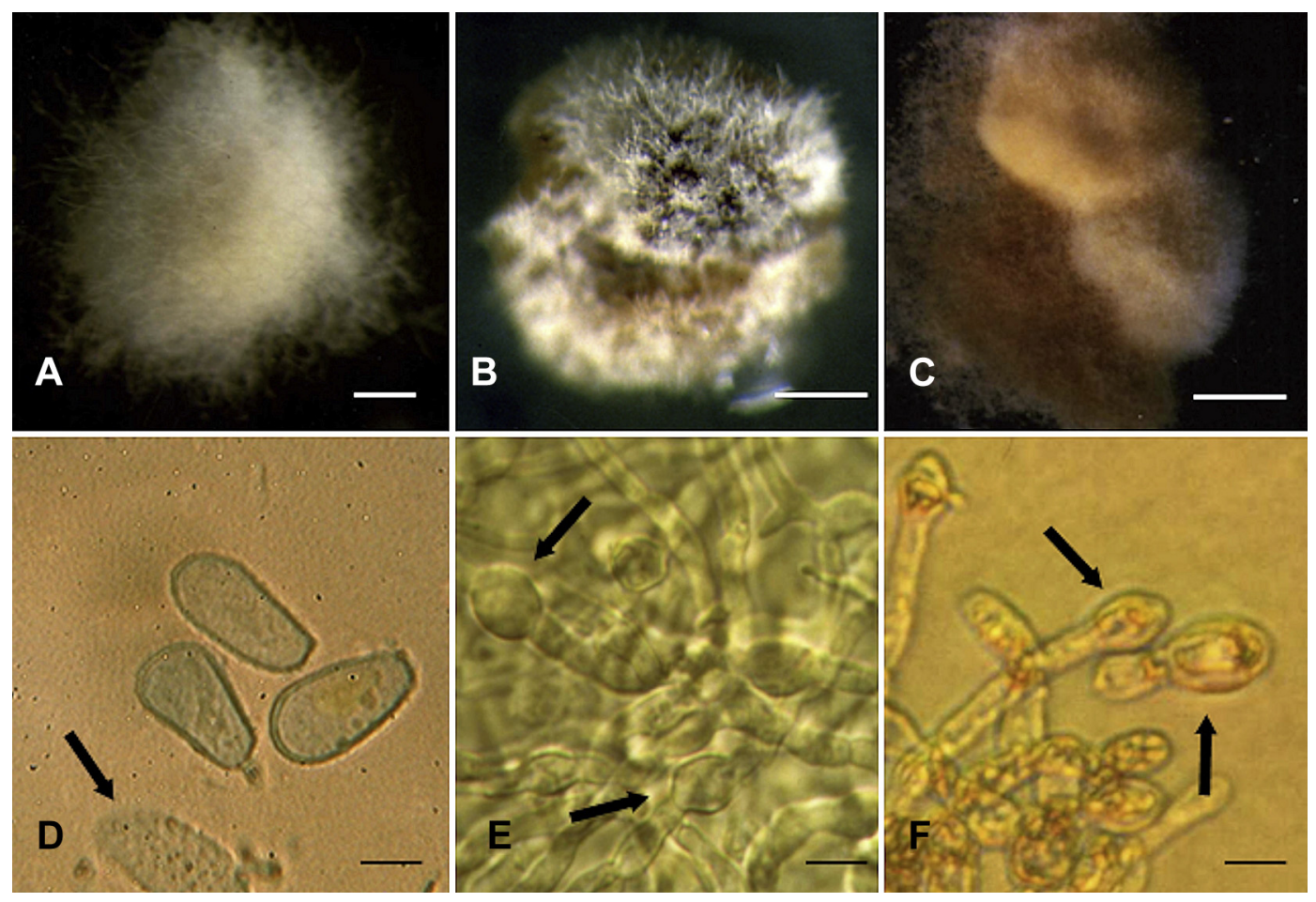

Fig 4 - Established cultures of Melampsoridium hiratsukanum and spore-like bodies produced in culture. (A) A vegetative colony, off-white, with a dense covering of long, aerial hyphae, giving the colony a fluffy appearance and an undefined margin. Scale bar $=1 \mathrm{~mm}$. (B) A reproductive colony, showing a rough, callus-like surface, with stromatal areas varying in colour, and a cover of short aerial hyphae. Scale bar $=2 \mathrm{~mm}$. (C) A colony exhibiting three distinct areas differing in compactness and colour, and suggesting that one particular sporeling had the upper hand in each area. Scale bar = $2 \mathrm{~mm}$. (D) Immature, ovoid to ellipsoid urediniospore-like bodies (centre) and a faintly echinulate urediniospore-like body (arrow) observed on a ten-week-old reproductive colony. Scale bar $=10 \mu \mathrm{m}$. (E) Thick-walled hyphal swellings (arrows) produced in the microsorus-like structure of an eight-week-old colony. Scale bar $=10 \mu \mathrm{m}$. (F) Two-celled, teliospore-like bodies, varying in length and shape, in the stromatal area of an 11-week-old reproductive colony. Scale bar $=10 \mu \mathrm{m}$. (For interpretation of the references to colour in this figure legend, the reader is referred to the web version of this article.)

A comparison of monthly colony growth rates on the media without BSA (average 25 colonies per medium) showed that HG1 produced the greatest axenic growth of $M$. hiratsukanum, followed by SH1 and HG1Y. On these last two media colony growth rates were similar (Fig 3A-C), and even the growth rate of HG1 did not differ from the other two. However, the growth rate of these three basic media differed from QMS-1, on which it was significantly lower (Fig 3D). Adding BSA to a medium improved the colony growth produced by that medium. The increase in growth obtained by adding BSA was greater on HG1, SH1 and HG1Y, but less marked on QMS-1. The improvement in growth obtained by adding BSA was not however statistically significant at $\mathrm{P}=0.05$ (Fig 3A-D). The very slight difference in colony growth between QMS-1 and QMS-1+BSA was to be attributed to the fact that both these media were poor at initiating and supporting saprotrophic growth (Fig 3D).

\section{Sporulation}

Spore-like bodies were produced on the orange to dark-brown stromatic areas of sporulating colonies, in the period ranging from 6 to 12 weeks after incubation. These spore-like bodies resembled immature urediniospore-like bodies, were thinwalled and lacked the characteristic ornamentation of mature spores, or had only a slight roughness (Fig 4D). The spore-like bodies were scattered all over the hyphal network or, more frequently, arose in places where there were microsorus-like structures. In these receptacle-like structures, prominent hyphal swellings could often be seen (Fig 4E). These hyphal swellings were intercalary, mostly interspersed with short hyphal cells, though a few swellings appeared on the hyphal tip. Because the ontogeny of these hyphal swellings was uncertain, it was not possible to ascertain whether they were infective (i.e. spores). Teliospore-like bodies, with a typical, twocelled, elongate shape were also seen (Fig 4F). Some teliospore-like bodies seemed as though they had germinated with a long and straight germ tube emanating from them. Overall, spore-like bodies were most profuse on HG1 and SH1+BSA.

\section{Molecular identification of axenic cultures}

Uniformly-sized gel bands (roughly 700bp) were seen with all the PCR products. Sequencing revealed that all amplicons had the same length (713 bp), and the ClustalW2 online 
alignment tool confirmed that they all had complete sequence homology. A BLAST nucleotide sequence comparison of the 5.8S gene and flanking ITS1 and ITS2 spacers in GenBank permitted the colonies to be securely identified as Melampsoridium hiratsukanum. All these colonies displayed $100 \%$ sequence overlap and $99 \%$ identity with two M. hiratsukanum isolates (GenBank accession nos. JN581985.1 and JN581987.1) as well as with an uncultured fungal clone, S209, in the database (GenBank accession no. FJ820697.1). One sequence (vegetative-type colony, isolate VT5) of $M$. hiratsukanum was deposited in GenBank (accession no. KC888944). This DNA-based assay obviously also confirmed the earlier identification of the rust fungus from field-collected inoculum, using structural and ultrastructural microscopy, as $M$. hiratsukanum.

\section{Discussion}

This is the first report of the successful establishment of saprophytic colonies of Melampsoridium hiratsukanum in vitro on non-living media. The colonies were maintained on nutrient media for up to eight months following initial two-step subculturing of mycelial primordia visible to the naked eye after 1-2 weeks, and of primary colonies after $1 \mathrm{~m}$.

Light and electron microscopy in conjunction with molecular biology techniques enabled both the environmental inoculum of $M$. hiratsukanum (urediniospore lots) and its axenic cultures to be securely identified. Ascertaining the exact identity of the microbial material on which the experiment is carried out is essential when attempting to grow cultivationresistant microbes in the laboratory for the first time.

One of the banes of the axenic culture of rust fungi is the risk that unwanted micro-organisms (common phylloplane fungi and bacteria) overgrow the microbe under study. Rust fungi are not naturally competitive as saprophytes (Turel 1971), and they represent a nutrient source for many microorganisms living on plants. Since the starting inoculum consisted of field-collected spore samples, 'microbial weeds' were an ever-present threat, as they are in all attempts to grow rusts in vitro (Scott \& Maclean 1969). The only way to overcome this problem is to seed a great number of Petri dishes, so that any contaminant occurrence will be proportionately diminished, and to inspect cultures daily and remove any contaminants promptly, as was done in the present study.

The extent to which axenic cultures of M. hiratsukanum succeeded in establishing themselves was closely related to the density of the inoculum. Although there was some evidence that high inoculum density negatively affected urediniospore germination and the initiation of saprotrophic growth (Kuhl et al. 1971), yet in a number of experiments growth was greatest where inoculum density had been highest, with sporelings stimulating each other to form colonies (Williams et al. 1966; Hartley \& Williams 1971; Maclean 1982). Those few germlings of $M$. hiratsukanum that happened to be cast over the medium with a density sufficient for them to stimulate each other to germinate and grow, aggregated and formed mycelial primordia. Such a cell-density regulatory pathway is thought to be mediated by small, diffusible signal molecules (exo-factors) secreted by the rust propagules, and they were among the first cases of cell-to-cell communication in fungi to be reported (Epstein et al. 1985; Moricca \& Ragazzi 2001). This type of cooperative behaviour is now widely known as 'quorum sensing' (Hogan 2006). We hypothesise that the collective production of quorum-signalling compounds benefits surrounding cells in the local spore population, causing greater spore germination, which later leads first to hyphal aggregations and then to the growth of visible mycelial initials in the agar medium.

It has been postulated that the initial instability of the axenic cultures of rust fungi generally is due to physiological and genetic differences (Coffey \& Shaw 1972). In the early stages of vegetative growth the colonies of $\mathrm{M}$. hiratsukanum were not yet fully established, since the fungus had to re-orient its metabolism before it could function in the changed environment (Scott \& Maclean 1969). That may explain the lower in vitro growth of the fungus at the start of the culturing experiment (lag phase), a phenomenon that has also been reported for other rust fungi (Bose \& Shaw 1974; Moricca \& Ragazzi 2001). Saprophytic colonies, on the other hand, consisted of mats of interwoven hyphae derived from a dense bulk spore cast. The sporelings in the hyphal masses were individuals in transition that were trying, with extreme difficulty, to adapt to an unusual existence, i.e. to switch from a biotrophic to a saprotrophic lifestyle (Maclean 1982). The agar medium exerted a strong selection pressure on individual sporelings, and those incapable of converting to saprophytic growth died as soon as they depleted the energy stored in the selfcontained metabolic reservoirs that are spores. By contrast, those genotypes that succeeded in making this switch survived and gave rise to the primary colonies. However, the primary colonies also varied, since they were mixtures of distinct individuals, each having its own degree of saprophytism. With time the most unfit individuals succumbed and were eliminated from the colonies, whereas those that survived formed established colonies. Established colonies were thus more homogeneous, and in consequence they began to grow at similar rates and to form stable associations, consisting of a few individuals or, ultimately, of only a single rust genotype.

Saprophytic growth is in any case an uncongenial mode of life even for strains adapted to laboratory conditions, and the selection pressure exerted by the artificial medium under the experimental conditions accounts for the frequent occurrence of colony variants.

The fact that viable saprophytic colonies of M. hiratsukanum arose on eight out of the twelve nutrient media tested, and that these media differed substantially from each other in their organic and inorganic constituents, provided circumstantial proof that the nutritional requirements of the fungus were relatively non-specific; this may offer clues on the factors influencing rust physiology and development. BSA was found to contain some unknown co-factors that stimulated colony formation on all the media to which it was added. HG1 and SH1 and their BSA-enriched variants produced extensive mycelium, confirming that these media were well able to produce axenic growth of the rust fungi (Moricca \& Ragazzi 2001). On the other hand the QMS media, which in earlier studies had 
supported in vitro growth of the closely related Melampsoridium betulinum (Yamaoka \& Katsuya 1984), gave varying results in this study. QMS-1 and QMS-1+BSA sustained the axenic growth of M. hiratsukanum, albeit only poorly, but QMS-5 and QMS-6, with or without BSA, failed to do so. QMS-5 and QMS-6, with or without BSA, differed from QMS-1 and QMS$1+B S A$ in that the former were supplemented with the plant hormone NAA $\left(0.001 \mathrm{~g} \mathrm{l}^{-1}\right)$ instead of the same amount of 2,4-D, and in that QMS-5 and QMS-5+BSA were also amended with $3.0 \mathrm{~g} \mathrm{l}^{-1}$ of Evans peptone and Difco Bacto-soytone, whereas QMS-1 and QMS-1+BSA received only $2.0 \mathrm{~g} \mathrm{l}^{-1}$ of these ingredients. But though these QMS media were as much as possible identical in all other respects, it cannot be ruled out that the poor results obtained with QMS-5 and QMS-6 and their BSA-modifications were caused by some unknown inhibiting compound(s) in them, or alternatively, by the lack of some required metabolite(s). An inbalance among the amino acids, leading to methionine toxicity, and a selective 'leakiness' of amino acids from the hyphae growing on artificial media have been suggested as possible explanations for differences in the growth initiation of Puccinia graminis Pers. on these media, and for the infrequency with which saprophytic colonies of that rust grew or were isolated from media similar to those used for M. hiratsukanum in this study (Howes \& Scott 1972; Maclean 1982). Alternatively there may have been an error in the preparation of the media. A common problem when working with enriched media devised to sustain the growth of biotrophic microbes is that some medium ingredients may precipitate and cause the final composition of the media to vary. This means that, when working with axenic cultures of rust fungi, even negative results must be interpreted with care, and care must also be taken when drawing conclusions about the nutritional requirements of these specialised micro-organisms.

The highly variable results obtained in growing rust fungi aseptically, and their occasional failure to grow, cannot be fully understood if it is not realised that an agarised medium is an inhospitable environment for these micro-organisms which, though they are parasitic, are also still plant symbionts (Maclean 1982). Rust fungi have evolved to survive in close association with their hosts. To grow in the laboratory, these micro-organisms must switch from a biotrophic lifestyle, with their hyphae bathed in the cell fluids of a living host, to a novel existence on a non-living, solid medium. This is a drastic change that can only be achieved through a gradual adaptation.

Despite all these difficulties, the advent of novel, highthroughput investigative tools is opening up new and unexpected ways to do cultivation-based research on recalcitrant microbes (Bull 2010). If a way to culture a rust fungus in vitro can be found it will ensure a continuous supply of contaminant-free mycelium of that fungus (and sometimes also of its propagules), which is a basic resource for molecular and non-molecular studies.

'Omics' investigations could greatly benefit from this valuable source material, which could help to uncover many aspects of this fascinating group of plant parasites. The application of experimental omics approaches might dramatically improve the efficiency of the axenic culturing of these microbes. Owing to the increasing availability of sequenced rust genomes, a knowledge of genes or gene families encoding enzymes that are essential for important biochemical pathways could soon become a reality (Duplessis et al. 2011). Such findings may be vital for a more accurate delineation of the nutritional requirements of rusts and thus bring about a marked improvement of current growth media, such an improvement has already occurred for other groups of obligate plant parasites (Lemos et al. 2003).

Novel ways to grow rusts in vitro are expected to have significant practical applications in plant pathology, shedding light on hitherto uninvestigated aspects of the plant-rust interactions and stimulating research on the epidemiology of plant diseases. The dual culture of $\mathrm{M}$. hiratsukanum and host cells in a contaminant-free environment such as a Petri dish would help elucidate the processes of host-parasite recognition and interaction (Ragazzi et al. 1995). The in vitro screening of plant pedigrees (plantlets) using axenically grown fungi could facilitate studies of disease resistance, which could in turn lead to the selective breeding of superior germplasm (Stelzer et al. 1999). Efforts to grow rust fungi in the laboratory have mostly been restricted to those fungi that have in the past caused serious disease outbreaks in the naturally grown plants or in agricultural crops, and the control of these fungi has imposed a heavy burden on governments and plant growers. Examples of such fungi are some prominent members of the genera Cronartium, Melampsora, and Puccinia (Williams et al. 1966; Coffey et al. 1970; Hollis et al. 1972; Yamazaki \& Katsuya 1987; Moricca \& Ragazzi 1994; Kinloch \& Dupper 1996).

Melampsoridium hiratsukanum has already caused serious damage to many alder formations in several European countries (Hantula \& Scholler 2006). It can therefore securely be ranked among the harmful pathogens that are worth attempting to grow in vitro. Important aspects of the biology and epidemiology of this fungus still await investigation. The protocol to culture M. hiratsukanum in a controlled chemical and physical environment as described here provides a simplified experimental system that can be used to control this fungus as well as to unravel details of its parasitic lifestyle that are still unknown.

\section{Acknowledgements}

We thank Dr. Giorgio Maresi, of the Edmund Mach Foundation, San Michele all'Adige (TN), Italy, for bringing the alder rust outbreak to their notice. We also thank Mrs Elisa Bruno, from the University of Florence, for expert technical assistance with SEM observations, and anonymous referees for useful comments. The study was funded in part by the University of Florence.

\section{R E F E R E N C E S}

Anonymous, 1951. Future of parasitology. Nature 168: 527-529. Bose A, Shaw M, 1974. In vitro growth of wheat and flax rust fungi on complex and chemically defined media. Canadian Journal of Botany 52: 1183-1195. 
Bull AT, 2010. The renaissance of continuous culture in the postgenomics age. Journal of Industrial Microbiology \& Biotechnology 37: 993-1021.

Coffey MD, Bose A, Shaw M, 1970. In vitro culture of the flax rust, Melampsora lini. Canadian Journal of Botany 48: 773-776.

Coffey MD, Shaw M, 1972. Nutritional studies with axenic cultures of the flax rust, Melampsora lini. Physiological Plant Pathology 2: 37-46.

Duplessis S, Cuomo CA, Lin Y-C, Aerts A, Tisserant E, Veneault-Fourrey C, Joly D, Hacquard S, Amselem J, Cantarel BL, et al., 2011. Obligate biotrophy features unraveled by the genomic analysis of rust fungi. Proceedings of the National Academy of Sciences of the United States of America 108: 9166-9171.

Epstein L, Laccetti L, Staples RC, Hoch HC, Hoose WA, 1985. Extracellular proteins associated with induction of differentiation in bean rust uredospore germlings. Phytopathology 75: 1073-1076.

Gardes M, Bruns TD, 1993. ITS primers with enhanced specificity for basidiomycetes - application to the identification of mycorrhizae and rusts. Molecular Ecology 2: 113-118.

Gäumann E, 1959. Die Rostpilze Mitteleuropas. . In: Beiträge zur Kryptogamenflora der Schweiz, vol. 12. Buchdruckerei Büchler, Bern1-407.

Hantula J, Kurkela T, Hendry S, Yamaguchi T, 2009. Morphological measurements and ITS sequences show that the new alder rust in Europe is conspecific with Melampsoridium hiratsukanum in eastern Asia. Mycologia 101: 622-631.

Hantula J, Scholler M, 2006. NOBANIS - invasive alien species fact sheet - Melampsoridium hiratsukanum From: Online Database of the North European and Baltic Network on Invasive Alien Species - NOBANIS. www.nobanis.org.

Hartley C, Williams PG, 1971. Morphological and cultural differences between races of Puccinia graminis f. sp. tritici in axenic culture. Transactions of the British Mycological Society 57: 137-144.

Harvey AE, Grasham JL, 1974. Axenic culture of the mononucleate stage of Cronartium ribicola. Phytopathology 64: 1028-1035.

Hiratsuka N, 1927. Studies on the Melampsoraceae of Japan. Journal of the Faculty of Agriculture, Hokkaido Imperial University, Sapporo 21: 1-41.

Hogan D, 2006. Talking to themselves: autoregulation and quorum sensing in fungi. Eukaryotic Cell 5: 613-619.

Hollis CA, Schmidt RA, Kimbrough JW, 1972. Axenic culture of Cronartium fusiforme. Phytopathology 62: 1417-1419.

Howes NK, Scott KJ, 1972. Sulphur nutrition of Puccinia graminis f. sp. tritici in axenic culture. Canadian Journal of Botany 50: 1165-1170.

Kinloch BB, Dupper GE, 1996. Genetics of Cronartium ribicola. I. Axenic culture of haploid clones. Canadian Journal of Botany 74: 456-460.

Kreisel H, Scholler M, 1994. Chronology of phytoparasitic fungi introduced to Germany and adjacent countries. Botanica Acta 107: 387-392.

Kuhl JL, Maclean DJ, Scott KJ, Williams PG, 1971. The saprophytic culture of Puccinia species from uredospores: experiments on nutrition and variation. Canadian Journal of Botany 49: 201-209.

Kurkela T, Hanso M, Hantula J, 1999. Differentiating characteristics between Melampsoridium rusts infecting birch and alder leaves. Mycologia 91: 987-992.

Lemos EG, Alves LM, Campanharo JC, 2003. Genomics-based design of defined growth media for the plant pathogen Xylella fastidiosa. FEMS Microbiology Letters 219: 39-45.
Maclean DJ, 1982. Axenic culture and metabolism of rust fungi. In: Scott KJ, Chakravorty AK (eds), The rust fungi. Academic Press, London, pp. 37-120.

Moricca S, Maresi G, 2010. Melampsoridium hiratsukanum reported for the first time on grey alder in Italy. New Disease Reports 21: 17.

Moricca S, Ragazzi A, 1994. Axenic culture of the aecial state of Cronartium flaccidum from Italy. Mycological Research 98: 1258-1262.

Moricca S, Ragazzi A, 1996. Culture characteristics and variation of Cronartium flaccidum isolates. Canadian Journal of Botany 74: 924-933.

Moricca S, Ragazzi A, 2001. Establishment of single-genotype axenic cultures from the haploid stage of the pine blister rust Cronartium flaccidum. Mycological Research 105: 1527-1532.

Moricca S, Ragazzi A, Naldini Longo B, 2000. In vitro growth of the aspen rust Melampsora larici-tremulae. Mycological Research 104: 1250-1257.

Murashige T, Skoog F, 1962. A revised medium for rapid growth and bioassays with tobacco tissue cultures. Physiologia Plantarum 15: 473-497.

Piątek M, Ronikier M, Miśkiewicz A, 2001. New records and new host for Melampsoridium hiratsukanum (Fungi, Uredinales) in Poland. Fragmenta Floristica et Geobotanica Polonica 8: $245-249$.

Põldmaa K, 1997. Explosion of Melampsoridium sp. on Alnus incana. Folia Cryptogamica Estonica 31: 48-51.

Ragazzi A, Moricca S, Dellavalle I, 1995. Growth of axenic cultures of Cronartium flaccidum on callus tissue from Pinus nigra var. laricio and Pinus sylvestris. European Journal of Forest Pathology 25: $31-37$.

Rigler-Hager H, Scheuer C, Zwetko P, 2003. Der Erlen-Rost Melampsoridium hiratsukanum in Österreich. Wulfenia 10: 135-143.

Roll-Hansen F, Roll-Hansen H, 1981. Melampsoridium on Alnus in Europe. M. alni conspecific with M. betulinum. European Journal For Plant Pathology 11: 77-87.

Saccardo PA, 1988. Sylloge Fungorum Omnium Hucusque Cognitorum, Vol. VII, Pars. I. Patavii 595.

Saccardo PA, 1905. Sylloge Fungorum Omnium Hucusque Cognitorum, Vol. XVII, Pars. VI, Supplementum Universale. Patavii 464.

Sánchez Márquez S, Bills GF, Zabalgogeazcoa I, 2008. Diversity and structure of the fungal endophytic assemblages from two sympatric coastal grasses. Fungal Diversity 33: 87-100.

Schenk RU, Hildebrandt AC, 1972. Medium and technique for induction and growth of monocotyledonous and dicotyledonous plant cell cultures. Canadian Journal of Botany 50: 199-204.

Scott KJ, Maclean DJ, 1969. Culturing of rust fungi. Annual Review of Phytopathology 7: 123-146.

Sert HB, Sümbul H, 2005. First report of Melampsoridium hiratsukanum infecting alder (Alnus orientalis var. orientalis) in Turkey. Plant Pathology 54: 241.

Staples RC, 2000. Research on the rust fungi during the twentieth century. Annual Review of Phytopathology 38: 49-69.

Stelzer HE, Doudrick RL, Kubisiak TL, Nelson CD, 1999. Prescreening slash pine and Cronartium pedigrees for evaluation of complementary gene action in fusiform rust disease. Plant Disease 83: 385-389.

Szabo I, 2002. First report of Melampsoridium hiratsukanum on common alder in Hungary. Plant Pathology 51: 804.

Trotter A, 1914. Flora Italica Cryptogama. Uredinales. Pars I 421.

Turel FLM, 1971. Pathogenicity and developmental differences of three saprophytically growing isolates of the flax rust fungus Melampsora lini race 3. Canadian Journal of Botany 49: $1993-1997$. 
Williams PG, Scott KJ, Kuhl JL, 1966. Vegetative growth of Puccinia graminis f. sp. tritici in vitro. Phytopathology 56: 1418-1419.

Williams PG, 1984. Obligate parasitism and axenic culture. In: Bushnell WR, Roelfs AP (eds), The Cereal Rusts. Academic Press, Orlando, FL. USA, pp. 399-430.

Wilson M, Henderson DM, 1966. British Rust Fungi. Cambridge Univ Press, Cambridge, UK 384.
Yamazaki S, Katsuya K, 1987. Axenic cultures of Cronartium quercuum and their pathogenicity. Annals of the Phytopathological Society of Japan 53: 643-646.

Yamaoka Y, Katsuya K, 1984. Study on axenic cultures of Melampsora chelidonii-pierotii, M. coleosporioides and Melampsoridium betulinum. Transactions of the Mycological Society of Japan 25: 435-444. 